\title{
BMJ Open Extent and determinants of catastrophic health expenditure for tuberculosis care in Chongqing municipality, China: a cross-sectional study
}

\author{
Weixia Duan, ${ }^{1,2}$ Wen Zhang, ${ }^{1}$ Chengguo Wu, ${ }^{1}$ Qingya Wang, ${ }^{1}$ Ya Yu, ${ }^{1}$ Hui Lin, ${ }^{3}$ \\ Ying Liu, ${ }^{1}$ Daiyu $\mathrm{Hu}^{1}$
}

To cite: Duan W, Zhang W,

Wu C, et al. Extent and determinants of catastrophic health expenditure for tuberculosis care in Chongqing municipality, China: a crosssectional study. BMJ Open 2019;9:e026638. doi:10.1136/ bmjopen-2018-026638

- Prepublication history for this paper is available online. To view these files, please visit the journal online (http://dx.doi. org/10.1136/bmjopen-2018026638).

Received 14 September 2018 Revised 19 February 2019 Accepted 28 February 2019

D Check for updates

(C) Author(s) (or their employer(s)) 2019. Re-use permitted under CC BY-NC. No commercial re-use. See rights and permissions. Published by BMJ.

${ }^{1}$ Department of Prevention, Chongqing Institute of Tuberculosis Prevention and Treatment, Chongqing, China ${ }^{2}$ The center of Laboratory Medicine, Chongqing Occupational Diseases Prevention Hospital, Chongqing, China

${ }^{3}$ Department of Epidemiology, The Third Military Medical University, Chongqing, China

\section{Correspondence to} Professor Ying Liu; 910981960@qq.com and Professor Daiyu $\mathrm{Hu}$; hukaixiou@263.net

\section{ABSTRACT}

Objective To investigate the extent and associations of patient/diagnostic delay and other potential factors with catastrophic health expenditure (CHE) for tuberculosis (TB) care in Chongqing municipality, China.

Design A cross-sectional study.

Setting Four counties of Chongqing municipality, China. Participants A total of 1199 patients with active pulmonary TB beyond 16 years and without mental disorders were consecutively recruited in the four counties' designated TB medical institutions.

Outcome measures The incidence and intensity of CHE for TB care were described. The association between patients' 'sociodemographic and clinical characteristics such as patient delay, diagnostic delay, forms of TB, health insurance status and hospitalisation and CHE were analysed using univariate and multivariate logistic regression.

Results The incidence of CHE was $52.8 \%$ and out-ofpocket (OOP) payments were $93 \%$ of the total costs for TB care. Compared with patients without delay, the incidence and intensity of CHE were higher in patients who had patient delay or diagnostic delay. Patients who experienced patient delay or diagnostic delay, who was a male, elderly ( $\geq 60$ years), an inhabitant, a peasant, divorced/widow, the New Cooperative Medical Scheme membership had greater risks of incurring CHE for TB care. Having a higher educational level appeared to be a protective factor. However, hospitalisation was not associated with CHE after controlling for other variables.

Conclusion The incidence and intensity of CHE for TB care are high, which provides baseline data about catastrophic costs that TB-related households faced in Chongqing of China. Variety of determinants of CHE implicate that it is essential to take effective measures to promote early seeking care and early diagnosis, improve the actual reimbursement rates of health insurance, especially for outpatients, and need more fine-tuned interventions such as precise poverty alleviation to reduce catastrophic costs of the vulnerable population.

\section{INTRODUCTION}

Tuberculosis (TB) is one of the top 10 causes of death and the leading cause of a single infectious disease (above HIV/AIDS) worldwide.

\section{Strengths and limitations of this study}

- The study provides new data about tuberculosis (TB)-related households facing catastrophic costs and the determinants of catastrophic health expenditure (CHE) for TB care in China.

- The study highlights the importance of early care seeking and diagnosis of TB.

- Our findings will provide valuable information for policymakers to take fine-tuned interventions to decrease catastrophic costs for vulnerable TB-affected households.

- Some self-reported data such as dates for onset of symptoms and healthcare seeking may have been affected by recall bias.

- The non-medical costs and indirect costs were not taken into account, which may underestimate the extent of CHE for TB care and should be considered in the future study.

In 2017, about 10.0 million people developed TB disease and 1.6 million deaths caused by TB globally. China has the second largest burden of TB in the world, accounting for $9 \%$ of all cases. ${ }^{1}$ Poverty is not only strongly associated with TB incidence but also a cause and a devastating outcome of TB. ${ }^{2}$ Therefore, ТВ is not only a serious infectious disease but also a severe public health problem worldwide. 'End TB strategy', a plan announced by the WHO to end the global TB epidemic, aims to reduce TB death rate by $95 \%$ and cut new cases by $90 \%$ between 2015 and 2035, and no affected families face catastrophic costs due to TB by $2020 .{ }^{3}$ However, the projected 2015 baseline is not yet available. ${ }^{3}$ Achieving zero TB-induced catastrophic costs for households is too great to realise because the financial burden for patients with TB is extremely high in low-income, middle-income and high-income countries. ${ }^{4-7}$ For instance, the mean treatment costs per drug-sensitive TB patient 
are \$39-\$858 in Africa, \$149-\$724 in China and €3427$€ 10282$ in the European Union. ${ }^{468}$

Catastrophic health expenditure (CHE) is a widely used index to calculate the burden of medical costs on households at a national level and is often incurred by households who have to pay out-of-pockets (OOP) for health services. ${ }^{9} 10$ Thus, the family may have to sacrifice the consumption of other goods and services necessary for their well-being. ${ }^{10}$ There are various definitions of CHE and no one gold standard for measuring it. ${ }^{11}{ }^{12}$ WHO has defined CHE as OOP payment for direct healthcare spending exceeds $40 \%$ of a household's capacity, ${ }^{10}$ while many studies defined CHE as OOP payment for healthcare that exceeds a specified proportion of annual household income which often set the threshold at 10\%-25\%. ${ }^{11} 1314$ According to the end TB strategy, it is now recommended to measure catastrophic costs incurred when the total costs exceed $20 \%$ of the annual household income. ${ }^{15}$ Eradicating catastrophic costs for TB-affected families is essential to ascertain the progress of universal health coverage (UHC) and social protection. However, the data about CHE for TB care are limited.

A recent systematic review indicated that approximately a third of households with a TB patient experienced TB-associated catastrophic costs. ${ }^{5}$ For instance, the incidence of CHE for TB was 32.4\% in Puducherry of India, $78.1 \%$ in Benin and $44 \%$ in Nigeria. ${ }^{11}{ }^{16}$ In China, more than two-thirds of TB-related households experienced CHE overall, and $46.7 \%$ of the households still experienced CHE after reimbursement by the New Cooperative Medical Scheme (NCMS) in rural areas. ${ }^{17} 18$ Additionally, households with members having $\mathrm{TB}$ are $~ 1.8$ times more likely to suffer CHE than those without. ${ }^{19}$ Therefore, it is essential to reduce the economic burden of patients with $\mathrm{TB}$ and save their families from CHE.

To reduce the economic burden on patients with TB, a 'free TB service policy' has been implemented in many countries. ${ }^{8021}$ Although the policy has been conducted for many years, patients with TB still suffer from the high costs of TB treatment, which often forces their families into catastrophe and poverty in low-income and middle-income countries, such as in China, India, Peru, Ethiopia and Tajikistan. ${ }^{16-18} 22{ }^{23}$ In China, the free TB service policy includes free X-ray examination and free sputum smear test for patients once with suspected TB at first visit, free first-line anti-TB drugs (6 months for new patients and 8 months if previously treated), three free sputum smear tests and one free X-ray test during anti-TB treatment. ${ }^{18}$ Also, there are three essential government-led complementary health insurances to cover some extra expenditures beyond the free TB service policy in China, including the NCMS for rural farmers, the Medical Insurance for Urban Residents (MIUR) and the Medical Insurance for Urban Employees (MIUE) ${ }^{18}$ Health insurance is the least for rural farmers followed by that for local urban residents, while it for urban employees is the most. However, the financial protection remains insufficient though China has dramatically expanded health insurance coverage. ${ }^{19}$

According to a few studies conducted in China, Nigeria, Indonesia and Benin, the factors determining CHE for TB care include age, sex, number of family members, urban residence, educational level, being a breadwinner, job loss, health insurance status, poor households, adverse prediagnosis stage, treatment at a private facility, ratio of patient income to total household income, hospitalisation and previous of TB treatment. ${ }^{1131724}$ However, the factors associated with CHE among patients with TB remain not well elucidated. Considering fact that delay in TB diagnosis was not only a significant challenge of TB control and prevention programmes in low-income and middle-income settings but also was an vital risk factor increases the risk of transmission and economic costs to patients and communities at large, ${ }^{25} 26$ we planned to explore the associations between the patient and diagnostic delay and CHE for TB care. Also, the extent of CHE and other risk factors related to $\mathrm{CHE}$ are investigated as well. Consequently, a cross-sectional study was performed in Chongqing municipality, which was an economic and industrial hub of the southwest region of China with a heavy burden of TB.

\section{METHODS}

\section{Study sites and participants}

This cross-sectional study was conducted in four counties of Chongqing from March 2013 to August 2014. The TB epidemic was high in Chongqing, which ranked in the top 10 among the most upper TB burden provinces in China. The TB notification rate of Chongqing in 2015 had declined to 70.8 cases per 100000 populations from the peak of 106 cases per 100000 in 2005, but still above the average TB incidence of China. Recent years, $\sim 20000$ patients were reported with $\mathrm{TB}$ in Chongqing, making up $2.5 \%$ of all notified TB cases in China. ${ }^{27}$ There are 39 districts/counties in Chongqing. According to the Chongqing Statistical Yearbook 2015, the real GDP per capita was $47850 ¥$. Urban population accounts for $59.6 \%$ of the total population. The four counties with similar levels of economic development and similar human geographical environment were selected as the study sites. These four counties are among the middle-income counties in Chongqing, have both villages and cities and are in the process of urbanisation. In Chongqing, the reimbursement ratio in different counties was different. The reimbursement ratio of medical expenses was $0 \%-60 \%$ by MIUE, $0 \%-50 \%$ by MIUR and $0 \%-45 \%$ by NCMS for outpatients and $65 \%$ by MIUE, $35 \%$ by MIUR and $35 \%$ by NCMS for inpatients in Chongqing.

From March to December in 2013, all registered active pulmonary TB (PTB) patients excluding those aged $<16$ years or with mental disorders were recruited consecutively in the designated $\mathrm{TB}$ medical institutes of the four counties. Because extrapulmonary TB, tuberculous pleuritis, drug-resistant PTB and patients with PTB not 
registered in counties' designated TB medical institutes were not covered by the free $\mathrm{TB}$ service policy during the period of research, only registered active PTB were included. Totally, 1290 patients with PTB were qualified, of who 61 refused to participate due to poor clinical conditions and 30 questionnaires were not completed. Thus, a total of 1199 patients were included in the study. All participants had access to free TB treatment and were prospectively followed throughout the treatment period.

\section{Data collection}

All data were collected in these four counties' designated TB medical institutes. The study was based on a well-structured questionnaire and patients' medical records. All participants at the local TB-designated medical institutes were interviewed face to face by a trained TB staff using the questionnaire. The following data were obtained: covered personal information, socioeconomic information (age, sex, residence, occupation, education, marital status, number of family members and household income and so on) and history of disease (forms of TB, date of first onset of suspected TB symptoms, date of first visit to any health provider, date of PTB diagnosis and direct medical costs for TB care). Clinic information (patient delay, diagnostic delay, forms of $\mathrm{TB}$, health insurance status and hospitalisation) and exact date of TB diagnosis were checked against the patients' medical records. A 6-month or 8-month treatment regimen was recommended by the WHO. The follow-up survey was conducted with patients with TB till completion of the treatment. The treatment costs were collected every month by the trained TB staff. The staff interviewed each participant and then checked invoices or financial accounting systems to ensure accuracy. OOP payments and reimbursements of the direct medical costs in different periods of services (prediagnosis, diagnosis and treatment) were collected per individual and checked invoices or financial accounting systems as well. All costs were indicated in Ren Min Bi (RMB).

\section{Definitions \\ Pulmonary TB}

PTB was diagnosed based on the pathological, clinical and radiological findings, and confirmed through bacteriological and histological examinations, which were strictly performed according to the Chinese diagnostic criteria for PTB (WS-288-2008). ${ }^{28}$

\section{Patient delay}

Patient delay is determined as a time interval from the first onset of TB symptoms to the first visit to any health provider; if the time interval lasts for $>14$ days, it is considered as a 'delay'. ${ }^{29}$

\section{Diagnostic delay}

Diagnostic delay is defined as a time interval between a patient's first visit to any health provider and the final diagnosis as TB; if the time interval lasts for $>14$ days, it is considered as a delay. ${ }^{29}$

\section{Prediagnosis}

Prediagnosis is the period from the onset of TB symptoms to the first visit to a local designated TB medical institution. The period of diagnosis is from the first visit to a local designated TB medical institution to the diagnosis of TB. The period of treatment is the full course of TB treatment.

\section{Direct medical costs}

Direct medical costs are composed of consultation fees, laboratory tests, X-rays, medical tests and drugs during the period of prediagnosis, diagnosis and treatment.

\section{P payments}

OOP payments are regarded as the direct medical costs paid by patients themselves.

\section{Measuring the incidence and intensity of CHE}

CHE is usually assessed by incidence and intensity. According to the definition of CHE in several previous studies, ${ }^{11} 1314$ we defined 'catastrophic' as the OOP payments of total medical costs for TB care exceeding $10 \%$ of the annual household income in this study. Head count (HC) is used to measure the incidence of CHE, while the mean gap (MG) and mean positive gap (MPG) are used to reflect the intensity of CHE. HC means the percentage of households whose OOP payments equal or exceed $10 \%$ of their annual income to the total number of households. MG is the average amount by which OOP payments, as a proportion of annual household income, exceeds the threshold. MPG is equal to $\mathrm{MG} / \mathrm{HC}$, the excess expenditure per household experiencing CHE. The methods used in measuring HC, MG and MPG are based on the previous study. ${ }^{14}$

\section{Statistical analysis}

Data were double entered and checked using EPI Data V.3. Data analysis was performed using SPSS V.18.0. Continuous variables were presented as medians and IQRs, while categorical variables were presented as numbers and percentages (\%). Pearson's $\chi^{2}$ test was used in univariate analyses to identify factors associated with the CHE and ORs with 95\% CIs were computed. All variables with a $\mathrm{p}<0.05$ in the univariate analysis were included in the multivariate model. A multivariate logistic regression model using a backward elimination method was used to assess the determinants of $\mathrm{CHE}$ and to calculate adjusted odds ratios (aOR) and 95\% CIs. A two-sided $p$ value of $<0.05$ was considered statistically significant.

\section{Patient and public involvement}

Patients and the public were not involved in the design or planning of the study.

\section{RESULTS}

\section{Patient characteristics}

The characteristics of these patients with PTB are summarised in table 1. A total of 1199 patients with PTB were enrolled in the study. The proportion of men 
Table 1 Sociodemographic and clinical characteristics of the study participants $(n=1199)$

\begin{tabular}{lll}
\hline Variables & Patients $(\mathbf{n})$ & Per cent \\
\hline Sex & & \\
$\quad$ Male & 839 & 70.0 \\
$\quad$ Female & 360 & 30.0 \\
Age (years) & & \\
$\leq 40$ & 532 & 44.4 \\
$41-59$ & 402 & 33.5 \\
$\geq 60$ & 265 & 22.1 \\
\hline
\end{tabular}

Residential status

\begin{tabular}{|c|c|c|}
\hline Inhabitant & 848 & 70.7 \\
\hline Migrant & 351 & 29.3 \\
\hline \multicolumn{3}{|l|}{ Marital status } \\
\hline Single & 340 & 28.4 \\
\hline Married & 795 & 66.3 \\
\hline Divorced/widow & 64 & 5.3 \\
\hline \multicolumn{3}{|l|}{ Educational level } \\
\hline Primary or below & 382 & 31.9 \\
\hline Junior high & 356 & 29.7 \\
\hline High school and above & 461 & 38.4 \\
\hline \multicolumn{3}{|l|}{ Occupation } \\
\hline Unemployed & 302 & 25.2 \\
\hline Employed & 327 & 27.3 \\
\hline Peasant & 353 & 29.4 \\
\hline Student & 96 & 8.0 \\
\hline Retiree & 121 & 10.1 \\
\hline \multicolumn{3}{|l|}{ Family size } \\
\hline $1-3$ & 887 & 74.0 \\
\hline $4-8$ & 312 & 26.0 \\
\hline \multicolumn{3}{|l|}{ Health insurance status } \\
\hline None & 130 & 10.8 \\
\hline NCMS & 548 & 45.7 \\
\hline MIUR & 230 & 19.2 \\
\hline MIUE & 249 & 20.8 \\
\hline Other insurance plan & 42 & 3.5 \\
\hline \multicolumn{3}{|l|}{ Hospitalisation } \\
\hline Yes & 191 & 15.9 \\
\hline No & 1008 & 84.1 \\
\hline \multicolumn{3}{|l|}{ Forms of TB } \\
\hline Smear-negative PTB & 892 & 74.4 \\
\hline Smear-positive PTB & 307 & 25.6 \\
\hline \multicolumn{3}{|l|}{ Patient delay } \\
\hline Yes & 635 & 53.0 \\
\hline No & 564 & 47.0 \\
\hline Median (IQR) (days) & $16(3-52)$ & \\
\hline \multicolumn{3}{|l|}{ Diagnostic delay } \\
\hline Yes & 516 & 43.0 \\
\hline
\end{tabular}

Continued
Table 1 Continued

\begin{tabular}{lcl}
\hline Variables & Patients (n) & Per cent \\
\hline No & 683 & 57.0 \\
Median (IQR) (days) & $9(3-33)$ & \\
Household annual income (RMB) & \\
Mean & 42200 \\
Median (IQR) (days) & $35000(20000-56000)$
\end{tabular}

MIUE, Medical Insurance for Urban Employees; MIUR, Medical Insurance for Urban Residents; NCMS, New Cooperative Medical Scheme; PTB, pulmonary TB; TB, tuberculosis.

to women involved in this study was 2.3:1. More than three-quarters of patients were in their labour age (16-59 years), and the average age of the patients was 43.9 years, with a median age of 44 years. Approximately $30 \%$ of patients were migrants. Two-thirds of patients were married and received at least junior high school education. About one-quarter of patients were unemployed, about $30 \%$ patients were peasants and $8.0 \%$ patients were students. Approximately three-quarters of the households had one to three family members. In the majority, $89.2 \%$ of the patients had health insurance and about half of the patients had NCMS. Only $15.9 \%$ of patients had been hospitalised in the intensive period. Approximately three-quarters of patients were smearing negative. Of the total participants, $53.0 \%$ and $43.0 \%$ patients experienced patient and diagnostic delay, with a median (IQR) of $16(3-52)$ and 9 (3-33) days measured in days, respectively. Patients' average annual household income was $42200 ¥$, with a median (IQR) of $35000 ¥(20000-56000$ $¥)$.

\section{Direct medical costs for TB in different periods of medical treatment}

The OOP costs and health insurance reimbursement during the prediagnosis, diagnosis and treatment period are presented in table 2. Expenses in the prediagnosis period were all paid by OOP, accounting for nearly half of the total cost. Excluding the fees covered by free TB service policy, around $7 \%$ of costs were reimbursed by health insurance during the treatment period, but no costs were reimbursed during the period of prediagnosis and diagnosis. The median total direct medical costs paid by a TB patient were $4085 ¥$, about $93 \%$ of which was paid by patients themselves.

\section{Incidence and intensity of CHE}

Table 3 shows that $52.8 \%(633 / 1199)$ of all TB-related households experienced CHE. On average, healthcare payments for TB were $18.1 \%$ higher than the threshold value $(10 \%)$. For households experiencing CHE, the MPG was $34.2 \%$ higher than the threshold. The incidence of CHE in patients experiencing patient delay or diagnostic delay was $11 \%$ or $9.7 \%$ more than those not suffering patient delay or diagnostic delay, respectively. The intensity measure was also higher for the group of 
Table 2 Direct medical costs for TB care in different periods of services $(n=1199)$

\begin{tabular}{|c|c|c|c|c|c|c|}
\hline \multirow{2}{*}{$\begin{array}{l}\text { Costs in different } \\
\text { periods (services) }\end{array}$} & \multicolumn{2}{|c|}{ Out-of-pockets } & \multicolumn{2}{|c|}{$\begin{array}{l}\text { Health insurance } \\
\text { reimbursement }\end{array}$} & \multicolumn{2}{|l|}{ Total } \\
\hline & Median & IQR & Median & IQR & Median & IQR \\
\hline Diagnosis* & 157 & $121-250$ & 0 & 0 & 157 & $121-250$ \\
\hline Treatment† & 1792 & $834-3050$ & 0 & $0-501$ & 1966 & 1000-3723 \\
\hline
\end{tabular}

Expenses excludes the costs of the free-TB policy reduction and exemption.

${ }^{*}$ The expenses excluded the cost of one-time free chest X-ray and sputum smear examination.

†The expenses excluded anti-TB drugs (6 months for new patients, 8 months if previously treated), three times sputum smear tests and one time $\mathrm{X}$-ray test during anti-TB treatment.

TB, tuberculosis.

experiencing patient delay or diagnostic delay than the group without delay.

\section{Determinants of CHE}

Table 4 shows the influence of different variables on CHE for TB care using a Pearson's $\chi^{2}$ test. There were many factors associated with CHE, including patient delay, diagnostic delay, sex, age, resident status, marital status, educational level, occupation, health insurance status and hospitalisation. Those factors were included in the multivariate logistic regression.

Logistic regression produced a wide range of determinants related to CHE (table 5). Independent determinants of CHE were patient delay (aOR, 1.342; 95\% CI 1.043 to 1.726 ), diagnostic delay (aOR, $1.540 ; 95 \% \mathrm{CI}$ 1.195 to 1.983 ), male (aOR, $1.141 ; 95 \%$ CI 1.066 to 1.877 ), age $\geq 60$ years (aOR, 2.117; 95\% CI 1.281 to 3.498 ), inhabitant (aOR, 1.455 ; 95\% CI 1.084 to 1.951 ), divorced or a widow (aOR, 2.211; 95\% CI 1.093 to 4.475 ), peasant (aOR, 2.205; 95\% CI 1.522 to 3.194), high school and above (aOR, 0.542; 95\% CI 0.356 to 0.826 ) and as NCMS membership (aOR, 1.688; 95\% CI 1.071 to 2.661). However, hospitalisation was not related to CHE after controlling for other variables (aOR, 1.342; 95\% CI 0.950 to 1.897$)$.

\section{DISCUSSION}

For the first time, global TB targets aimed to decrease catastrophic costs associated with TB. Evaluating the incidence and intensity of TB-related CHE not only provided insight into the UHC but also reflected the economic burden of patients with $\mathrm{TB}$ and their families. In this study, the incidence of CHE for TB care was $52.8 \%$ after reimbursement, which was lower than the reported rates of $66.8 \%, 65 \%$ and $78.1 \%$ in other cities of China, Nigeria and Benin, respectively, using the same CHE measurement methods. ${ }^{11} 1317$ However, the figure was a little higher than that in Indonesia $(50 \%)$ when they involved in patients with multi-drug resistant tuberculosis (MDR-TB), ${ }^{24}$ and much higher than the rate of CHE incurred by general population or patients with non-communicable chronic disease in China. ${ }^{19}$ In that TB inequitably affects poor people and households in poorer economic quintiles are more at risk of suffering CHE and impoverishment. ${ }^{19}{ }^{30}$ The MG was $18.1 \%$ and the MPG was $34.2 \%$ for TB in our study, both were higher than that in Nigeria $(6.0 \%, 9.3 \%)^{1113}$ and in Benin $(7.8 \%, 14.8 \%)^{13}$ but lower than that in other cities of China $(40.8 \%$, $62.2 \%)^{17}$ because we did not take non-medical costs into account while other studies did. Although many studies claimed that non-medical costs and indirect costs related to $\mathrm{TB}$ care were a severe financial burden for patients with TB and their households, ${ }^{5} 3132$ some studies found that these costs were not high compared with direct medical costs. ${ }^{18334}$ Thus, the extent of patients incurring catastrophic costs in this study population may be underestimated but remain reliable.

Although all patients in this study have access to free TB treatment and the majority of them have health insurance, they had a heavy financial burden of OOP payments and more than half of them incurred catastrophic costs. The phenomena is common in China, ${ }^{818} 35$ there may be

\begin{tabular}{|c|c|c|c|c|c|}
\hline \multirow{2}{*}{$\begin{array}{l}\text { Catastrophic health } \\
\text { expenditure }\end{array}$} & \multicolumn{2}{|c|}{ Patient delay } & \multicolumn{2}{|c|}{ Diagnostic delay } & \multirow{2}{*}{$\begin{array}{l}\text { All } \\
(n=1199)\end{array}$} \\
\hline & Yes & No & Yes & No & \\
\hline Head count (\%) & 58.0 & 47.0 & 58.3 & 48.6 & 52.8 \\
\hline Mean gap (\%) & 21.1 & 14.6 & 19.3 & 17.2 & 18.1 \\
\hline Mean positive gap (\%) & 36.5 & 31.1 & 33.0 & 35.3 & 34.2 \\
\hline
\end{tabular}

CHE, catastrophic health expenditure; TB, tuberculosis. 
Open access

Table 4 Single factor analysis of catastrophic health expenditure in patients

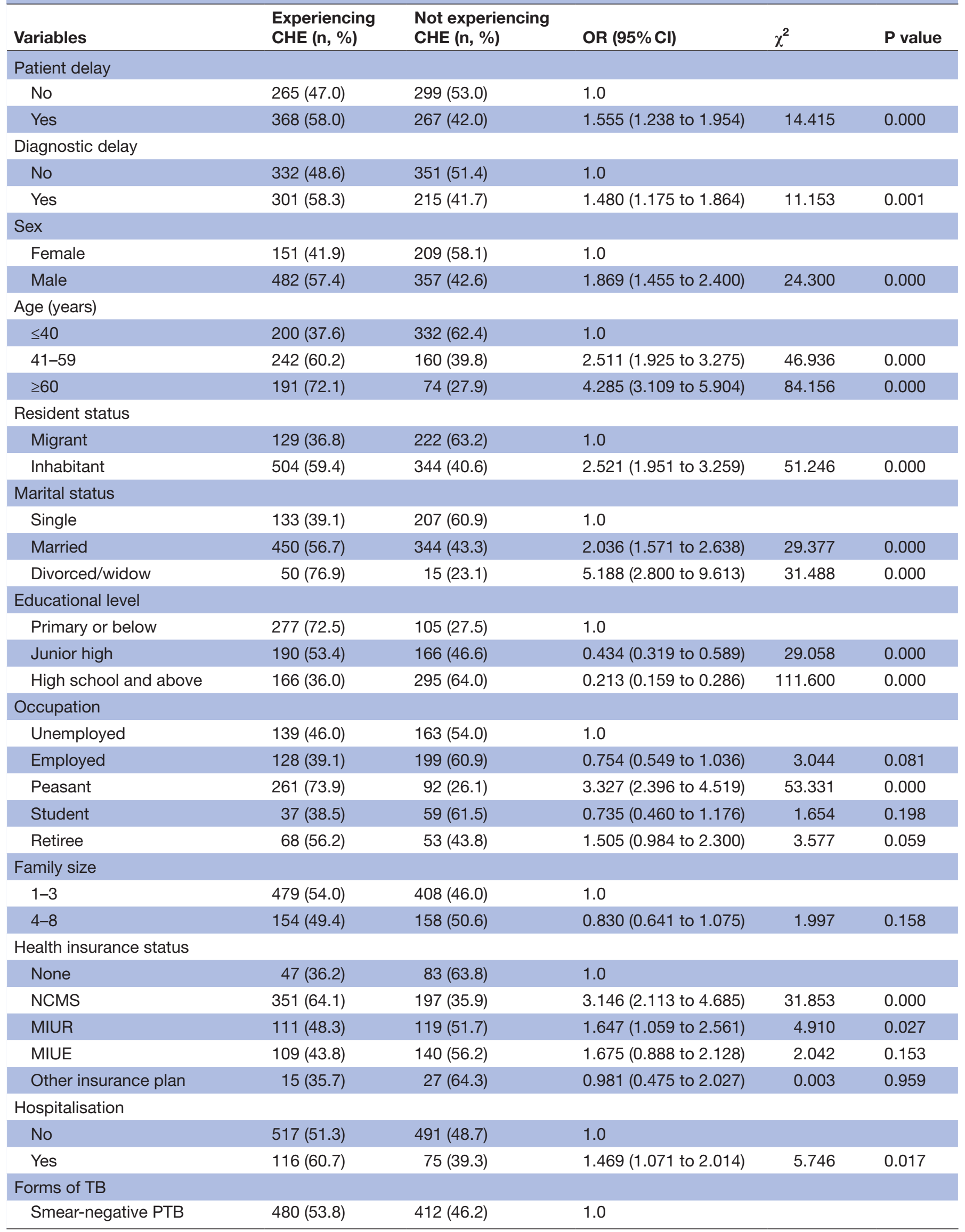

Continued 
Table 4 Continued

\begin{tabular}{clllll}
\hline Variables & $\begin{array}{l}\text { Experiencing } \\
\text { CHE (n, \%) }\end{array}$ & $\begin{array}{l}\text { Not experiencing } \\
\text { CHE (n, \%) }\end{array}$ & OR (95\% Cl) & $\chi^{2}$ & P value \\
\hline Smear-positive PTB & $153(49.8)$ & $154(50.2)$ & $0.853(0.658$ to 1.105$)$ & 1.448 & 0.229 \\
\hline
\end{tabular}

CHE, catastrophic health expenditure; MIUE, Medical Insurance for Urban Employees; MIUR, Medical Insurance for Urban Residents; NCMS, New Cooperative Medical Scheme; PTB, pulmonary TB; TB, tuberculosis.

three reasons to explain it: (i) many associated healthcare costs are not covered in the free TB policy, for example, payment for drugs of ancillary and liver protection, and extra diagnostic tests. ${ }^{28} 36$ (ii) Driven by profits, doctors may prescribe additional medicines and tests. ${ }^{37}$ (iii) The reimbursement ratio for outpatient services is low and often ignored, as well as the actual implementation strength of inpatients reimbursement was weak. ${ }^{38-40}$ Besides, we also found nearly half of all OOP payments were paid before diagnosis, which was similar to many previous studies. ${ }^{62341}$ This cost had aroused particular concern in that it not only reflected the economic burden on families for obtaining a diagnosis but also may act as an obstacle for poor patients to access timely TB care.

Delay in diagnosis had a massive impact on TB transmission in the community, aggravating the severity and mortality, resulting in an unfavourable treatment outcome and significantly increasing total patient costs. ${ }^{42-45}$ In this study, we further investigated the relationship between patient/diagnostic delay and CHE for TB care among patients with TB. We found about half patients encountered patient delay or diagnostic delay, who incurred more serious CHE than those without delay. Also, we demonstrated that patient delay and

Table 5 Independent determinants of CHE for TB care using a logistic regression model

\begin{tabular}{|c|c|c|c|c|c|}
\hline Variables & $\beta$ & SE & Wald & $P$ value & OR $(95 \% \mathrm{Cl})$ \\
\hline Patient delay (Ref: without delay) & 0.294 & 0.128 & 5.251 & 0.022 & $1.342(1.043$ to 1.726$)$ \\
\hline Diagnostic delay (Ref: without delay) & 0.431 & 0.129 & 11.145 & 0.001 & $1.540(1.195$ to 1.983$)$ \\
\hline Sex (Ref: female) & 0.347 & 0.144 & 5.764 & 0.016 & 1.141 (1.066 to 1.877$)$ \\
\hline Age (years) (Ref: $\leq 40$ ) & & & 8.557 & 0.014 & \\
\hline $41-59$ & 0.336 & 0.187 & 3.216 & 0.073 & 1.399 (0.969 to 2.019$)$ \\
\hline$\geq 60$ & 0.75 & 0.256 & 8.554 & 0.003 & 2.117 (1.281 to 3.498$)$ \\
\hline Resident status (Ref: migrant) & 0.375 & 0.15 & 6.247 & 0.012 & 1.455 (1.084 to 1.951$)$ \\
\hline Marital status (Ref: single) & & & 6.239 & 0.044 & \\
\hline Married & -0.005 & 0.192 & 0.001 & 0.977 & 0.995 (0.683 to 1.448$)$ \\
\hline Divorced/widow & 0.794 & 0.36 & 4.87 & 0.027 & $2.211(1.093$ to 4.475$)$ \\
\hline Educational level (Ref: primary or below) & & & 8.224 & 0.016 & \\
\hline Junior high & -0.294 & 0.187 & 2.485 & 0.115 & 0.745 (0.517 to 1.074$)$ \\
\hline High school and above & -0.612 & 0.215 & 8.114 & 0.004 & 0.542 (0.356 to 0.826$)$ \\
\hline Occupation (Ref: unemployed) & & & 28.975 & 0.000 & \\
\hline Employed & 0.025 & 0.176 & 0.02 & 0.887 & 1.025 (0.726 to 1.448$)$ \\
\hline Peasant & 0.791 & 0.189 & 17.475 & 0.000 & 2.205 (1.522 to 3.194$)$ \\
\hline Student & 0.368 & 0.279 & 1.745 & 0.187 & 1.446 (0.837 to 2.497$)$ \\
\hline Retiree & -0.318 & 0.257 & 1.53 & 0.216 & 0.727 (0.439 to 1.204$)$ \\
\hline Health insurance (Ref: none) & & & 6.355 & 0.174 & \\
\hline NCMS & 0.524 & 0.232 & 5.087 & 0.024 & $1.688(1.071$ to 2.661$)$ \\
\hline MIUR & 0.358 & 0.248 & 2.085 & 0.149 & $1.431(0.880$ to 2.327$)$ \\
\hline MIUE & 0.158 & 0.266 & 0.353 & 0.553 & 1.171 (0.695 to 1.974$)$ \\
\hline Other insurance plan & 0.169 & 0.398 & 0.181 & 0.671 & 1.184 (0.543 to 2.583$)$ \\
\hline Hospitalisation (Ref: not hospitalisation) & 0.294 & 0.176 & 2.784 & 0.095 & $1.342(0.950$ to 1.897$)$ \\
\hline
\end{tabular}

The variables that showed association with CHE $(p<0.05)$ in the univariate analysis were included in the multivariate model.

$\mathrm{CHE}$, catastrophic health expenditure; MIUE, Medical Insurance for Urban Employees; MIUR, Medical Insurance for Urban Residents; NCMS,

New Cooperative Medical Scheme; Ref, reference group; TB, tuberculosis. 
diagnostic delay were crucial determinants of CHE. Consistently, Laokri et al found that patient delay over 1 month was an independent determinant of incurring catastrophic expenditure. ${ }^{13}$ In addition, a large number of studies had revealed that patient delay and diagnostic delay were independent factors associated with total OOP costs. ${ }^{2325343546}$ Actually, prolonged delays in TB diagnosis are still prevailing problems in many countries in many low-income and middle-income countries, such as in Ethiopia, Zambia, Tanzania, Mozambique, Indonesia and so on. ${ }^{43-50}$ Therefore, it is vital to take measures to shorten the delay in diagnosis.

Patient delay may be related to the fact that patients do not take minor symptoms seriously in its early stage and will pay greater attention to it until symptoms become more severe. ${ }^{38}$ In addition, many sociodemographic and economic factors contribute to patient delay. ${ }^{29}$ Therefore, we should adopt comprehensive measures to facilitate patients to seek care early, such as strengthening TB health education to the public and adopting a precise poverty alleviation to increase the income of poverty-stricken patients. Early diagnosis is difficult due to the vast percentage of asymptomatic PTB patients and non-availability of rapid, accurate and cost-effective tests in many settings. ${ }^{51}$ In this study, only one-quarter of patients has been confirmed bacteriological and mainly based on traditional methods. Rapid molecular methods were not frequently used in Chongqing in 2013. Hence, more rapid, accurate and affordable methods are urgently needed to shorten the time of diagnosis.

Multivariate regression analysis indicated that demographic factors such as age, sex, marital status, occupation, resident status and education level independently affected the risk of catastrophic costs for TB care. Consistent with previous studies in Nigeria and other cities of China, age was an essential determinant of CHE, ${ }^{11}{ }^{17}$ but only patients who were $\geq 60$ years significantly affect CHE after removing the confounding factors in our study. Usually, men were the breadwinner of a family, thus we and Ukwaja et al found male patients were more easily to experience CHE, ${ }^{11}$ but Zhou et al showed that gender had no significant associations with CHE. ${ }^{17}$ In contrast with a previous study in China, ${ }^{17}$ we found marital status was an independent factor related with CHE, but the family size and hospitalisation were not determinants of CHE because we grouped different segments of the household population. Besides, only $15.9 \%$ of patients had been hospitalised during the treatment, much lower than the figure in a previous study of $55 \% .{ }^{17}$ Generally, people with low educational level also have less economic income, and thus we all demonstrated patients with less education were more likely to incur CHE. ${ }^{11}{ }^{13}$ Compared with inhabitants, migrants had a smaller proportion of patients being male, elderly or peasant and a higher proportion of patients with high educational level, thus migrant patients were less likely to experience CHE compared with inhabitant patients.
We found that patients covered by NCMS, compared with those without any type of health insurance, were more likely to experience CHE. A series of studies conducted in China have demonstrated that NCMS could not relieve the financial burden of TB-related medical costs and had a partial effect on protecting TB-related households from CHE. ${ }^{173952}$ Compared with patients not covered by NCMS, patients with TB covered by the NCMS only had a $5 \%$ higher reimbursement rate regarding outpatient and total medical costs in Zhejiang and Sichuan provinces of China. ${ }^{39}$ NCMS is designed exclusively for rural residents particular for peasants, who are usually in low-income status. Also, the majority of patients without health insurance were migrants. In contrast with the previous study in China, we did not find MIUR or MIUE has any positive effect on reducing CHE. ${ }^{17}$ It may be due to the actual reimbursement rate of health insurance is low in China. These three types of health insurances largely cover inpatient services but the benefit package for outpatient care vary widely. In fact, a lot of areas existed to ignore reimbursements to varying degrees in China, especially for outpatient services. ${ }^{40}$ In research, there was no reimbursement for medical costs during prediagnosis and diagnosis, which further indicated that the actual reimbursement rate is very low. Thus, so far health insurance plan did not actually help to relieve the financial burden for patients with TB in China. Consequently, the health insurance policy should be implemented effectively.

This study has some limitations. First, some data collected based on self-reporting could not be checked, which may be subjected to recall bias. Second, the data in this study were collected 4years ago, and the per capita income has increased from 2014 to 2017. However, China's free TB service policy has not changed in recent years, and TB inequitably affects poor people. Therefore, the CHE remains a problem for TB now in China. Third, we did not use the new definition of "catastrophic costs due to TB' recommended by WHO, which is the total (direct and indirect) costs exceeding 20\% of annual household income recently. ${ }^{15}$ Although the threshold $(10 \%)$ we set was lower than the new definition and we did not take indirect costs into account, it may also be valuable to present the proportion of TB-affected patients (and their households) facing catastrophic costs if direct costs alone are counted. ${ }^{15}$ Furthermore, the data about the CHE associated with TB were limited worldwide and correlational research has been conducted only in three cities in China. Consequently, our study may add some new data of CHE for TB care in China.

\section{CONCLUSION}

Although all patients have access to free TB service policy and the majority of them have health insurance, patients with TB still shoulder a high burden of OOP payments and experience high incidence and intensity of CHE for TB care in Chongqing, China. Except for sociodemographic factors, patient delay and diagnostic delay are essential 
determinants of CHE for TB care, which highlights the significance of early care seeking and early diagnosis. In addition, NCMS aggravates the catastrophic costs, which implicates that it is essential to improve the actual reimbursement rates of health insurance, especially for outpatients. Furthermore, more fine-tuned interventions such as precise poverty alleviation are essential to taken for vulnerable patients with TB to reduce their catastrophic costs. Overall, our results have provided some baseline data about CHE for TB, which may give some clues for a further prospective study.

Acknowledgements We thank the participants who have generously devoted their time and the staff in the study sites where this work has been conducted for their support in making this work done. Great thanks to Professor Bradley Chen from National Yang-Ming University of Taiwan and Professor Chen-Yuan Chiang from International Union against Tuberculosis and Lung Disease for their professional suggestions in manuscript writing.

Contributors $\mathrm{DH}$ : designed the study and drafted the manuscript. YL: designed the study, implemented the survey and analysed the data. WD: designed the study, analysed the data and drafted the manuscript. WZ, CW, QW and YY: implemented the survey and collected data. HL: analysed the data and drafted the manuscript. All authors read and approved the final version of the manuscript.

Funding This work was supported by the research funding from Chongqing Municipal Health Bureau (No 2012-1-087, 2017MSXM124 and 2017MSXM125).

Competing interests None declared.

\section{Patient consent for publication Obtained.}

Ethics approval The study was approved by the Ethical Committee of Chongqing Institute of Tuberculosis Prevention and Treatment, Chongqing, China.

Provenance and peer review Not commissioned; externally peer reviewed.

Data sharing statement No additional data are available.

Open access This is an open access article distributed in accordance with the Creative Commons Attribution Non Commercial (CC BY-NC 4.0) license, which permits others to distribute, remix, adapt, build upon this work non-commercially, and license their derivative works on different terms, provided the original work is properly cited, appropriate credit is given, any changes made indicated, and the use is non-commercial. See: http://creativecommons.org/licenses/by-nc/4.0/.

\section{REFERENCES}

1. World Health Organization. Global tuberculosis report 2018. Geneva, France, WHO/CDS/TB: World Health Organization, 2018:20.

2. Jackson S, Sleigh AC, Wang GJ, et al. Poverty and the economic effects of TB in rural China. Int J Tuberc Lung Dis 2006;10:1104-10.

3. World Health Organization. The end TB strategy. Geneva, Switzerland: World Health Organization, 2014.

4. Diel R, Vandeputte J, de Vries G, et al. Costs of tuberculosis disease in the European Union: a systematic analysis and cost calculation. Eur Respir J 2014;43:554-65.

5. Tanimura T, Jaramillo E, Weil D, et al. Financial burden for tuberculosis patients in low- and middle-income countries: a systematic review. Eur Respir J 2014;43:1763-75.

6. Ukwaja KN, Modebe O, Igwenyi C, et al. The economic burden of tuberculosis care for patients and households in Africa: a systematic review. Int J Tuberc Lung Dis 2012;16:733-9.

7. Laurence YV, Griffiths UK, Vassall A. Costs to Health Services and the Patient of Treating Tuberculosis: A Systematic Literature Review. Pharmacoeconomics 2015;33:939-55.

8. Long $\mathrm{Q}$, Smith $\mathrm{H}$, Zhang $\mathrm{T}$, et al. Patient medical costs for tuberculosis treatment and impact on adherence in China: a systematic review. BMC Public Health 2011;11:393.

9. Choi JW, Choi JW, Kim JH, et al. Association between chronic disease and catastrophic health expenditure in Korea. BMC Health Serv Res 2015;15:26.

10. Xu K, Evans DB, Kawabata K, et al. Household catastrophic health expenditure: a multicountry analysis. Lancet 2003;362:111-7.

11. Ukwaja KN, Alobu I, Abimbola S, et al. Household catastrophic payments for tuberculosis care in Nigeria: incidence, determinants, and policy implications for universal health coverage. Infect Dis Poverty 2013;2:21.

12. Pal R. Measuring incidence of catastrophic out-of-pocket health expenditure: with application to India. Int J Health Care Finance Econ 2012;12:63-85

13. Laokri S, Dramaix-Wilmet M, Kassa F, et al. Assessing the economic burden of illness for tuberculosis patients in Benin: determinants and consequences of catastrophic health expenditures and inequities. Trop Med Int Health 2014;19:1249-58.

14. Wagstaff A, van Doorslaer E. Catastrophe and impoverishment in paying for health care: with applications to Vietnam 1993-1998. Health Econ 2003;12:921-33.

15. World Health Organization. Tuberculosis patient cost surveys: a hand book. Geneva: World Health Organization, 2017. License: CC BY-NCSA 3.0 IGO.

16. Prasanna T, Jeyashree K, Chinnakali P, et al. Catastrophic costs of tuberculosis care: a mixed methods study from Puducherry, India. Glob Health Action 2018;11:1477493.

17. Zhou C, Long Q, Chen J, et al. Factors that determine catastrophic expenditure for tuberculosis care: a patient survey in China. Infect Dis Poverty 2016;5:6.

18. Chen $\mathrm{S}$, Zhang $\mathrm{H}$, Pan $\mathrm{Y}$, et al. Are free anti-tuberculosis drugs enough? An empirical study from three cities in China. Infect Dis Poverty 2015;4:47.

19. Li Y, Wu Q, Xu L, et al. Factors affecting catastrophic health expenditure and impoverishment from medical expenses in China: policy implications of universal health insurance. Bull World Health Organ 2012;90:664-71.

20. Holtgrave DR, Crosby RA. Social determinants of tuberculosis case rates in the United States. Am J Prev Med 2004;26:159-62.

21. Mauch V, Bonsu F, Gyapong M, et al. Free tuberculosis diagnosis and treatment are not enough: patient cost evidence from three continents. Int J Tuberc Lung Dis 2013;17:381-7.

22. Wingfield T, Boccia D, Tovar M, et al. Defining catastrophic costs and comparing their importance for adverse tuberculosis outcome with multi-drug resistance: a prospective cohort study, Peru. PLoS Med 2014;11:e1001675

23. Asres A, Jerene D, Deressa W. Pre- and post-diagnosis costs of tuberculosis to patients on Directly Observed Treatment Short course in districts of southwestern Ethiopia: a longitudinal study. $J$ Health Popul Nutr 2018;37:15.

24. Fuady A, Houweling TAJ, Mansyur M, et al. Catastrophic total costs in tuberculosis-affected households and their determinants since Indonesia's implementation of universal health coverage. Infect Dis Poverty 2018;7:3.

25. Mesfin MM, Newell JN, Madeley RJ, et al. Cost implications of delays to tuberculosis diagnosis among pulmonary tuberculosis patients in Ethiopia. BMC Public Health 2010;10:173.

26. Getnet F, Demissie M, Assefa N, et al. Delay in diagnosis of pulmonary tuberculosis in low-and middle-income settings: systematic review and meta-analysis. BMC Pulm Med 2017:17:202.

27. Wu B, Yu Y, Xie W, et al. Epidemiology of tuberculosis in Chongqing, China: a secular trend from 1992 to 2015. Sci Rep 2017;7:7832.

28. WS-288-2008. Diagnostic criteria for pulmonary tuberculosis. Ministry of health of the People's Republic of China 2008.

29. Li Y, Ehiri J, Tang S, et al. Factors associated with patient, and diagnostic delays in Chinese TB patients: a systematic review and meta-analysis. BMC Med 2013;11:156.

30. Rocha C, Montoya R, Zevallos K, et al. The Innovative Socioeconomic Interventions Against Tuberculosis (ISIAT) project: an operational assessment. Int J Tuberc Lung Dis 2011;15(Suppl 2):50-7.

31. Li Q, Jiang W, Wang $Q$, et al. Non-medical financial burden in tuberculosis care: a cross-sectional survey in rural China. Infect Dis Poverty 2016;5:5:5.

32. da Silva Antunes R, Pinto M, Trajman A. Patient costs for the diagnosis of tuberculosis in Brazil: comparison of Xpert MTB/RIF and smear microscopy. Int J Tuberc Lung Dis 2014;18:547-51.

33. Bay V, Tabarsi P, Rezapour A, et al. Cost of Tuberculosis Treatment: Evidence from Iran's Health System. Osong Public Health Res Perspect 2017;8:351-7.

34. Pan HQ, Bele S, Feng Y, et al. Analysis of the economic burden of diagnosis and treatment of tuberculosis patients in rural China. Int $J$ Tuberc Lung Dis 2013;17:1575-80.

35. Qiu S, Pan $\mathrm{H}$, Zhang $\mathrm{S}$, et al. Is tuberculosis treatment really free in China? A study comparing two areas with different management models. PLoS One 2015;10:e0126770.

36. Liu $\mathrm{Q}$, Smith $\mathrm{H}$, Wang $\mathrm{Y}$, et al. Tuberculosis patient expenditure on drugs and tests in subsidised, public services in China: a descriptive study. Trop Med Int Health 2010;15:26-32. 
37. Zhan S, Wang L, Yin A, et al. Revenue-driven in TB control-three cases in China. Int $J$ Health Plann Manage 2004;19(Suppl 1):S63-78.

38. Zhang T, Tang S, Jun G, et al. Persistent problems of access to appropriate, affordable TB services in rural China: experiences of different socio-economic groups. BMC Public Health 2007;7:19.

39. Wei X, Zou G, Yin J, et al. Effective reimbursement rates of the rural health insurance among uncomplicated tuberculosis patients in China. Trop Med Int Health 2015;20:304-11.

40. Li W, Li X, Zhang H, et al. An investigation of the current health insurance status of pulmonary tuberculosis cases without drug resistance in certain areas of China. Chin Prev Med 2012;13:401-5.

41. Ayé $\mathrm{R}$, Wyss $\mathrm{K}$, Abdualimova $\mathrm{H}$, et al. Household costs of illness during different phases of tuberculosis treatment in Central Asia: a patient survey in Tajikistan. BMC Public Health 2010;10:18.

42. Harris TG, Sullivan Meissner J, Proops D. Delay in diagnosis leading to nosocomial transmission of tuberculosis at a New York City health care facility. Am J Infect Control 2013;41:155-60.

43. Mahato RK, Laohasiriwong W, Vaeteewootacharn K, et al. Major Delays in the Diagnosis and Management of Tuberculosis Patients in Nepal. J Clin Diagn Res 2015;9:LC05-9.

44. Kuznetsov VN, Grjibovski AM, Mariandyshev AO, et al. Two vicious circles contributing to a diagnostic delay for tuberculosis patients in Arkhangelsk. Emerg Health Threats J 2014;7:24909.
45. Lui G, Wong RY, Li F, et al. High mortality in adults hospitalized for active tuberculosis in a low HIV prevalence setting. PLoS One 2014;9:e92077.

46. Aspler A, Menzies D, Oxlade O, et al. Cost of tuberculosis diagnosis and treatment from the patient perspective in Lusaka, Zambia. Int J Tuberc Lung Dis 2008;12:928-35.

47. Storla DG, Yimer S, Bjune GA. A systematic review of delay in the diagnosis and treatment of tuberculosis. BMC Public Health 2008;8:15.

48. Fuge TG, Bawore SG, Solomon DW, et al. Patient delay in seeking tuberculosis diagnosis and associated factors in Hadiya Zone, Southern Ethiopia. BMC Res Notes 2018;11:115.

49. Said K, Hella J, Mhalu G, et al. Diagnostic delay and associated factors among patients with pulmonary tuberculosis in Dar es Salaam, Tanzania. Infect Dis Poverty 2017;6:64.

50. Needham DM, Foster SD, Tomlinson G, et al. Socio-economic, gender and health services factors affecting diagnostic delay for tuberculosis patients in urban Zambia. Trop Med Int Health 2001;6:256-9.

51. Xu W, Lu W, Zhou Y, et al. Adherence to anti-tuberculosis treatment among pulmonary tuberculosis patients: a qualitative and quantitative study. BMC Health Serv Res 2009;9:169.

52. Xiang L, Pan $Y$, Hou S, et al. The impact of the new cooperative medical scheme on financial burden of tuberculosis patients: evidence from six counties in China. Infect Dis Poverty 2016;5:8. 